\title{
Review
}

\section{Truth and democracy}

\author{
Jeremy Elkins and Andrew Norris (eds.) \\ University of Pennsylvania Press, Philadelphia, PA, 2012, 352pp., (cloth), \\ ISBN: 978-0812243796, Ebook ISBN: 978-0812206227
}

Contemporary Political Theory (2014) 13, e7-e11. doi:10.1057/cpt.2013.22

You could call the pre-2008 era in America the age of 'truthiness' - to use the inspired coinage by modern sophist Stephen Colbert - or even, to quote the philosopher who gave us a theory of it at about the same time - the age of 'bullshit' (Frankfurt, 2005). The years that span the deceitful Bush campaign for the invasion of Iraq to the near collapse of the financial system were indeed characterized by something worse, and arguably more damaging to democracy, than outright lies: a profound lack of concern for truth, whether in the form of hard evidence or cold logic, in other words, according to Frankfurt, the very essence of bullshit.

Whether this era is fully over is open for debate. A somewhat promising sign is the comeback of the notion of truth on the philosophical stage. To the extent that political philosophy reflects general societal trends, it seems that any kind of move away from moral relativism or outright indifference to truth would be a sign of recovery. The volume put together by Jeremy Elkins and Andrew Norris under the title Truth and Democracy is undeniably part of that recovery, aiming to show not only why, but also how, truth matters to democracy.

The volume includes a collection of 18 essays by various authors from philosophy, political theory and history, some of whom are assigned the task of commenting on others, as well as a usefully problematized introduction by the co-editors and a reproduction of Harold Pinter's famous 2005 Nobel Prize lecture on 'Art, Truth, and Politics'. The volume is organized in four sections: (i) Opinion and Agreement; (ii) Authority and Justification; (iii) Decision and Deliberation; (iv) Truth and Public Reasons.

The ambition of the volume is to reintroduce truth into our impoverished political vocabulary as a relevant and in fact necessary category. It does so against, in large part (certain interpretations of), the views of Hannah Arendt and her post-modern heirs - moral relativists disguised as pragmatists (or vice-versa), such as Richard Rorty, and agonistic pluralists, such as Chantal Mouffe. It does so also against the later Rawls' stance of 'epistemic abstinence' - that is, the rejection of the relevance of truth for justifying the embrace of specific principles of justice as the proper set of 
rules for the social basis of cooperation. In an effort to take seriously the 'burdens of judgment' afflicting the possibility of political agreement even from the point of view of ideal theory, the Rawls of Political Liberalism famously banned the concept of truth underlying the claims of his earlier Theory of Justice, in favor of the supposedly less divisive concept of the 'reasonable'. Rawls did so, however, in ways that turned out to be uncomfortable for many Rawlsian deliberative democrats.

In the volume, at least four strategies are deployed, and sometimes combined, to defend the relevance of truth for democratic politics. The first consists in (i) focusing on the relevance of factual truth to democratic debates. While this is perhaps the most straightforward and least controversial strategy, recent history has shown that the argument is far from superfluous. Many essays fight the good fight on that front and easily win it. Other essays more ambitiously aim to reconquer truth as a general concept that includes moral/normative dimensions as well. In that category, one strategy consists in (ii) what Habermas would have called a 'transcendental' move: arguing that the concept of truth is the very condition of possibility for meaningful discourse in democratic politics, and is in fact required and implied by all the other concepts we resort to when arguing about justice (like the concepts of belief, assertion, judgment and so on). Another strategy, complementary to the previous one, consists in (iii) defending a minimal conception of truth and arguing that it is immune to the objections usually raised against thicker or more metaphysical conceptions. The fourth strategy consists in (iv) reclaiming for politics not just a minimal, non-metaphysical or otherwise partial conception of truth, but 'the whole truth'.

As it is impossible to do justice to the richness of all the contributions, let me just say a few words about the last two strategies, pursued, respectively, by Joshua Cohen and David Estlund, also because the fourth section in which they appear illustrates in substance and form the successful way the essays gathered in this volume answer and complement each other to move an existing debate to its frontier.

Cohen's approach to the conundrum raised by Rawls' rejection of the concept of truth consists in reinterpreting him as saying something like this: 'There is no available conception of truth that would be so minimal as to ensure overlapping consensus, or, if there is, it is not the one that people will intuitively associate with the concept of truth. So let's just not use the concept of truth altogether'. To this, Cohen's reply is to summarize: 'There is, actually, such a minimal conception of truth and that is the one people should associate with the concept of truth, which is necessary to our thinking about justice at all. This minimal conception is a political conception of truth, which we can develop on the model that you, Rawls, gave us of a political conception of justice'.

In the process of offering this solution, Cohen shows that Rawls was wrong in assuming that one could avoid the divisiveness induced by truth-claims when replacing truth with the apparently more modest concept of the 'reasonable'. At some point in the deliberation, we will have to make claims about which of the competing reasonable conceptions of justice put forward is the 'most reasonable' as 
well. This argument, in my view, definitively puts to rest the claim shared by Rawls and Arendt that the concept of truth is the divisive factor in our political disagreements. As Cohen rightly puts it, the use of truth in public discourse merely 'expresses the disagreement that we [already] have'. It does not provoke, let alone cause it.

Estlund's take on the problem is different. Although he shares Cohen's view that political liberalism cannot do without the truth, his solution consists in distinguishing between, on the one hand, the task of justifying to each other the superiority of a given law or principle of justice, which he argues we cannot but do in terms of truth-claims, and on the other hand, the task of justifying the imposition on others of the law or principle each of us deems true (or truest). The first task (justification per se) requires letting in 'the whole truth' - that is appeals to comprehensive doctrines - as opposed to a partial 'political' truth, which Estlund thinks is just an ersatz of truth and thus no truth at all (although, as Joshua Ober rightly points out in his commentary, it is unclear why Estlund thinks that the truth must be 'whole' or nothing).

The second task (legitimation), however, shifts the justificatory burden to a procedure acceptable to all reasonable (or qualified) points of view. This procedure, for Estlund, is the very deliberation process through which we exchange truth-claims, to the extent that this deliberation is capable of producing a single consensual outcome (a much more problematic assumption, incidentally, than it may seem at first sight, as clearly brought out in Bernard Yack's essay). In Estlund's words: '[T]he right procedural justification might refer to a procedure [e.g. deliberation] in which participants address the truth, in the comprehensive sense, about justice. If this procedural justification is itself acceptable to all reasonable points of view, then the Rawlsian principle of justification would be fully respected'.

Estlund's reconstruction of the relation between truth and democracy can afford to do entirely without the political conception of truth proposed by Cohen, because political truth is not enough for the first task (the justification of a view or policy), and it is unnecessary for the second (the justification for imposing it on others, or legitimation). Whatever deliberation (or some other collective decision-procedure) ends up producing as an outcome need not be true, but it will be accepted as reasonable by all qualified points of view.

In my view, Cohen offers the simplest and most satisfying way out of Rawlsian ambiguities without betraying the reasons behind Rawls' epistemic abstinence, even if this solution comes at the cost of saying that Rawls was wrong on some things. Estlund's solution, by contrast, seems to reproduce, on the legitimation side, the same problem that Cohen diagnoses in Rawls' approach: the notion of 'the reasonable' will not solve disagreements allegedly caused by appeals to the notion of truth; it will simply express them differently. What is interesting in Estlund's approach, though, is that it allows for the reintroduction of comprehensive doctrines in the public debate. This is so because, on Estlund's two-pronged interpretation, the legitimation of a given law or principle will not be performed by the comprehensive doctrine supporting that law or principle, but by the fact that it has survived the 
impartial deliberative process that pits truth-claims against each other. Deliberation may ideally produce a law or principle that meets the Rawlsian standard of public reason, but this is not decided at the outset by limiting what enters the discussion at the gate.

This solution is arguably more democratic and inclusive than Rawls' ex ante imposition of the filter of public reason, and in fact strikes me as more Habermasian than Rawlsian per se. However, it comes with its own ambiguities. What is the relation to truth of the procedure agreed on by all qualified points of view, namely deliberation? In Estlund's theory of 'epistemic proceduralism' (which he develops in his book Democratic Authority), the deliberative procedure can only satisfy the normative requirements implied by the notion of a 'qualified point of view' if it meets some minimal epistemic threshold, that is, if it tracks the truth more accurately than a random procedure. This requirement is supposed to ensure the avoidance of catastrophic harms, like genocide, unjust wars, economic collapse and so on.

Estlund's threshold of epistemic performance strikes me as too minimalistic for a legitimizing procedure, and I have myself argued that this minimalism is not even required, given that we can expect a much higher epistemic performance from a certain type of inclusive democratic deliberation. However, in any case, the fact is that on Estlund's account, truth unavoidably sneaks through the back door, not just at the level of the individual exchange of arguments, but at the level of the legitimizing procedure as well. Democratic deliberation is not supposed to always produce the 'true' answer, but it is legitimizing only as long as it is likely to produce truer answers, or true answers more often, than a random procedure. Therefore, it's not the case, even on Estlund's terms, that all we need at the level of the legitimizing procedure is the Rawlsian concept of the 'reasonable'. What we need is the concept of truth. Unless, of course, we shift the meaning of the 'reasonable' to mean 'probably true' - which, incidentally, is the interpretation that Habermas himself offered of Rawls' notion of the reasonable. However, if the reasonable is merely the probably true, there goes Rawls' epistemic abstinence (a probable truth is still a form of truth).

It seems to me that what these two key contributions taken together establish is that truth is inescapable for both political justification and political legitimation. Many of the other contributions to the volume provide strong arguments in that direction too. In fact, one of the few critics of the volume's task, Yack, blames deliberative democrats of both the Rawlsian and Habermasian strands for making moral/political justification and political legitimation dependent on each other in ways that too conveniently resolve the tension between truth and democracy, at various costs for each. However, despite making some excellent points, the critics, including Yack, are generally less convincing. Wendy Brown, for her part, claims that 'all powers are equally incapable of speaking the truth without endangering themselves' and 'if power cannot speak its own truth without undoing itself, then politics is not and cannot be a field of truth' - radical judgments she bases essentially on the authority of Arendt and Foucault, who themselves relied on rather limited (and now dated) social 
scientific evidence. What if, however, the essence of democratic power was its ability, unlike any other power, to be strengthened rather than weakened by a greater commitment to truth? This is one way to interpret, for example, the current Open Government initiatives currently taking place around the world, which consist in democratic (or at least democratizing) governments and public administrations releasing as much data as possible to the public and fostering transparency, participation and collaboration at every level of governance. This seems to me a case of power at least trying to speak its own truth and a direct, empirical refutation of Brown's prediction.

All in all, a few major conclusions emerge from the volume. Truth matters as a category for democratic politics. Truth-claims, however, must be accompanied by a healthy dose of skepticism. Citizens must be able to put forward an argument and at the same time be aware of and recognize its epistemic fragility. There is also consensus in the volume on the rejection of the falsely impartial model currently dominating the news media, according to which all opinions are equally worthy of being voiced and each point deserves a counterpoint, no matter how crazy, factually inaccurate or violating of the shared norms of valid discourses. The volume thus forms in my view a welcome and significant landmark in the 'epistemic turn' taken, in the last 15 years or so, by democratic theory generally and deliberative democracy specifically. ${ }^{1}$

\section{Note}

1 Full disclosure: Being an epistemic democrat myself, I'm deeply invested in the advent of this 'epistemic turn'. I have given my two cents on the subject of truth and politics in the last chapter of my own book Democratic Reason: Politics, Collective Intelligence, and the Rule of the Many (Princeton University Press, 2013), well before, sadly, I knew about this volume.

Hélène Landemore Yale University, New Haven, CT, USA. 